\title{
Common vs. distinct visuomotor control deficits in autism spectrum disorder and schizophrenia
}

Running title: Sensorimotor impairments, control and inhibition

Loïc Carment $^{\mathrm{a}, \mathrm{b}+}$, Elie Khoury ${ }^{\mathrm{c}+}$, Lucile Dupin ${ }^{\mathrm{a}, \mathrm{b}}$, Laura Guedj ${ }^{\mathrm{d}}$, Narjes Bendjemaa ${ }^{\mathrm{a}, \mathrm{b}, \mathrm{d}, \mathrm{e}}$, Macarena Cuenca $^{\text {b,e }}$, Marc A. Maier ${ }^{\text {b,f }}$, Marie-Odile Krebs ${ }^{\mathrm{a}, \mathrm{b}, \mathrm{d}}$, Påvel G. Lindberg ${ }^{\mathrm{a}, \mathrm{b}}$, Isabelle Amado $^{\mathrm{a}, \mathrm{b}, \mathrm{d}}$

Affiliations:

a. Institute of psychiatry and neuroscience of Paris, INSERM U1266, Université de Paris, Paris, France

b. Institut de psychiatrie, CNRS GDR3557, Paris, France

c. Hôpital Robert Debré, APHP, Paris, France

d. Resource Center for Cognitive Remediation and Psychosocial Rehabilitation (C3RP), Université de Paris, Hôpital Sainte-Anne, Paris, France

e. Centre de recherche clinique, Hôpital Sainte-Anne, Paris, France

f. Université de Paris, UMR 8002 CNRS, Paris, France

+ equal contribution of first and second authors

\section{Acknowledgement}

We thank the 'Delegation à la Recherche Clinique et l'Innovation' (DRCI), the Clinical Research Center (CRC) of Sainte-Anne Hospital and the C3RP neuropsychologists for their helpful contribution to this work. This study was supported by the "Fondation pour la Recherché Médicale" (FRM - DPP20151033970). The funders had no role in study design, data collection and analysis, decision to publish or preparation of the manuscript.

\section{Lay summary}

Autism spectrum disorder (ASD) and schizophrenia (SCZ) are neurodevelopmental disorders with partly overlapping and partly distinct clinical symptoms. Sensorimotor impairments rank among these symptoms, but it is less clear whether they are shared or distinct. In this study, we 
showed using a grip force task that sensorimotor impairments related to motor inhibition are common to ASD and SCZ, but more severe in ASD. Impaired motor anticipation may represent a further specific impairment in ASD.

\section{Abstract (250 words max)}

Autism spectrum disorder (ASD) and schizophrenia (SCZ) are neurodevelopmental disorders with partly overlapping clinical phenotypes including sensorimotor impairments. However, direct comparative studies on sensorimotor control across these two disorders are lacking. We set out to compare visuomotor upper limb impairment, quantitatively, in ASD and SCZ. Patients with ASD ( $\mathrm{N}=24)$ were compared to previously published data from healthy control participants $(\mathrm{N}=24)$ and patients with $\mathrm{SCZ}(\mathrm{N}=24)$. All participants performed a visuomotor grip force-tracking task in single and dual-task conditions. The dual-task (high cognitive load) presented either visual distractors or required mental addition during grip force-tracking. Motor inhibition was measured by duration of force release and from principal component analysis (PCA) of the participant's force-trajectory. Common impairments in patients with ASD and SCZ included increased force-tracking error in single-task condition compared to controls, a further increase in error in dual-task conditions, and prolonged duration of force release. These three sensorimotor impairments were found in both patient groups. In contrast, distinct impairments in patients with ASD included greater error under high cognitive load, and delayed onset of force release compared to SCZ. The PCA inhibition component was higher in ASD than SCZ and controls, correlated to duration of force release, and explained group differences in tracking error. In conclusion, sensorimotor impairments related to motor inhibition are common to ASD and SCZ, but more severe in ASD, consistent with enhanced neurodevelopmental load in ASD. Furthermore, impaired motor anticipation may represent a further specific impairment in ASD.

Keywords: neurodevelopmental disorder; schizophrenia; autism spectrum disorder; inhibitory dysfunction; sensorimotor control. 


\section{Introduction}

Sensorimotor symptoms, clinically operationalized through neurological soft signs (NSS), have been considered as behavioural markers of neurodevelopmental load in schizophrenia (Biswas, Malhotra, Malhotra, \& Gupta, 2007), as well as in autism spectrum disorder (Goldman et al., 2009; Jansiewicz et al., 2006). The common presence of NSS and shared multifactorial etiologies (characterized by an interaction between biological/genetic and environmental factors; Geschwind \& Levitt, 2007; Insel, 2010; Millan et al., 2016) are therefore consistent with a neuropathological continuum between these two disorders (Hirjak et al., 2014). However, there are also symptomatic differences: ASD is characterized by a core deficit in communication and social interactions, restricted interests and stereotyped behaviours (American Psychiatric Association, 2013), not found in SCZ. Conversely, specific deficits in SCZ concern delusions, hallucinations, disorganized behaviour and negative symptoms (American Psychiatric Association, 2013). Furthermore, ASD symptoms usually emerge in early childhood (Baumer \& Spence, 2018), those in SCZ typically during adolescence/early adulthood. Nonetheless, the hypothesis of a pathological neurodevelopmental continuum between autism and schizophrenia has been recently put forward, in part owing to the observation that many children with ASD develop psychosis later in life, and that schizophrenia patients often present atypical developmental histories (Martinez et al., 2017, 2019).

The presence of common NSS and other sensorimotor impairments, probed behaviourally (Gourion, Goldberger, Olie, Lôo, \& Krebs, 2004; Halayem et al., 2010; Krebs, Gut-Fayand, Bourdel, Dischamp, \& Olié, 2000; Mosconi \& Sweeney, 2015; Travers et al., 2015; Walther \& Mittal, 2016; Whyatt \& Craig, 2013) and neurophysiologically (Gomez-Pilar et al., 2017; Kana, Keller, Minshew, \& Just, 2007), have been extensively assessed, though usually not in a strictly comparative manner. These sensorimotor impairments seem to be central features in ASD (Mosconi \& Sweeney, 2015) and in SCZ (Walther \& Mittal, 2016; Walther \& Strik, 2012), and they potentially reflect a common underlying neurodevelopmental burden. Studying sensorimotor impairments in both disorders remains relevant for several reasons: these impairments (i) seem to be prevalent (up to $80 \%$ in autism (Mosconi \& Sweeney, 2015) and schizophrenia (Walther \& Strik, 2012)); (ii) they have a direct impact on daily functioning/quality of life (Bowie, Reichenberg, Patterson, Heaton, \& Harvey, 2006; Travers et al., 2017); (iii) they are of potential interest for (early) screening, since they may detect objective, prodromal signs (Caldani et al., 2017; Millan et al., 2016; Mosconi \& Sweeney, 2015; 
Térémetz et al., 2017); and (iv) they may promote better understanding of the underlying neuropathological mechanisms.

Separate studies in ASD and SCZ indicate impaired fine sensorimotor control (Neely et al., 2019; Walther \& Strik, 2012; Whyatt \& Craig, 2013), presence of NSS (Bachmann, Degen, Geider, \& Schröder, 2014; Halayem et al., 2010), and deficits in inhibitory cortical activity (Brandt et al., 2015; Kana et al., 2007; Noda et al., 2017; Oberman et al., 2010; SapeyTriomphe, Lamberton, Sonié, Mattout, \& Schmitz, 2019), with GABAergic dysfunction in ASD (Oberman et al., 2014) and SCZ (Radhu et al., 2013). Other symptoms are more specifically linked to ASD, such as presence of motor stereotypies (Goldman et al., 2009) and lack of motor anticipation (Fabbri-Destro, Cattaneo, Boria, \& Rizzolatti, 2008; Martineau, Schmitz, Assaiante, Blanc, \& Barthélémy, 2004; Schmitz, Martineau, Barthélémy, \& Assaiante, 2003). However, despite a growing literature comparing cognitive deficits between ASD and SCZ (Bölte, Rudolf, \& Poustka, 2002; Clark \& Lum, 2017; Martinez et al., 2017) comparative data on sensorimotor impairments are scarce (Martinez et al., 2019).

This study aimed at assessing patients with ASD through a visuomotor force-tracking paradigm previously used in patients with SCZ and healthy control participants (HC) (Teremetz et al., 2014). Tracking performance was assessed by measures of tracking error, force onset, release onset, and release duration, allowing for a direct comparison of potentially shared vs. distinct deficits in a grip force-tracking paradigm (Carment et al., 2019). In addition, we investigated the effect of cognitive load on visuomotor performance in ASD vs. SCZ (Carment et al., 2019). Based on the presumed continuum between ASD and SCZ (Hirjak et al., 2014) and given earlier onset and more severe neurodevelopmental impact in ASD (St Pourcain et al., 2017), we hypothesized that both groups would show common impairments in sensorimotor control but superposed with disorder-specific deficits (following the gradient ASD $>$ SCZ $>$ HC). Since ASD and SCZ have similar deficits in cognitive functions (Geschwind \& Levitt, 2007; Millan et al., 2016), we predicted that tracking performance in both groups would decrease with increasing cognitive load over that seen in control participants. We also predicted that both patient groups would show tracking deficits related to impaired motor inhibition, but that patients with ASD would show more severe sensorimotor impairments than those with SCZ (Biswas et al., 2007; Jansiewicz et al., 2006; Martinez et al., 2017), according to the gradient (ASD>SCZ>HC). In a previous study we have shown that principal component analysis (PCA) of force recordings during tracking results in a motor inhibition component that is significantly reduced in patients with SCZ (Térémetz et al., 2014). In this study, we predict that this PCA inhibitory component would also follow the gradient (ASD $>$ SCZ $>$ HC). Finally, since anticipation is considered to be 
deficient in ASD (Brisson, Warreyn, Serres, Foussier, \& Adrien, 2012; Schmitz et al., 2003; Wang et al., 2015), but less so or not in SCZ (Sailer, Eggert, Strassnig, Riedel, \& Straube, 2007), we expected temporal parameters to be affected in ASD, but not in SCZ.

\section{Materials and methods}

\section{Participants}

Twenty-four patients (6 females, 18 males, mean age \pm SD: $29 \pm 7 y$ ), fulfilling DSM-V criteria for ASD (American Psychiatric Association, 2013), were recruited in the University department (SHU) at Sainte-Anne Hospital, Paris, France. For patients with SCZ (6 females, 18 males, age \pm SD: $31 \pm 9 y$ ) and healthy controls (6 females, 18 males, age \pm SD: $30 \pm 7 y$ ), clinical and experimental data were obtained from a previous study (Carment et al., 2019). All patients were clinically stabilized, with or without a constant dose of atypical antipsychotics for at least one month (medicated: SCZ, n=24; ASD, n=6). An approximated intelligent quotient (aIQ) was obtained using the Wechsler Adult Intelligence Scale (WAIS-IV; Grégoire \& Wierzbicki, 2009) for SCZ and HC. Participants with an aIQ $<80$ were excluded. ASD patients with intellectual disability according to Autism Diagnostic Interview (ADI; Lord, Rutter, \& Le Couteur, 1994) and/or a diagnosed dyscalculia were excluded. The study received ethical approval (CPP ${ }^{\circ}$ AM7519-1-3364, Ile-de-France VIII) and all participants provided written informed consent.

\section{Clinical measures}

Clinical symptomatology (Table 1) was assessed using the Brief Psychiatric Rating Scale in all patients (Overall \& Gorham, 1962), the Positive and Negative Syndrome Scale (PANSS; Kay, Fiszbein, \& Opler, 1987) for SCZ, and ADI (Lord et al., 1994) for ASD. The global assessment of functioning (GAF; Jones, Thornicroft, Coffey, \& Dunn, 1995) was evaluated in both patient groups. Neurological soft signs (NSS; Krebs et al., 2000), extra-pyramidal symptoms (Simpson \& Angus, 1970), abnormal involuntary movements (Munetz \& Benjamin, 1988), selective attention (Stroop, 1935), and executive processing (WAIS-IV sub-scores 'similarities' and 'matrices') were assessed in all groups.

\section{Visuomotor grip force-tracking task}

All participants performed a visuomotor grip force-tracking task with their right hand according to our previously published protocol (see Figure 1; Carment et al., 2019). Participants had to match a right-to-left scrolling line (target force) as accurately as possible with their grip force 
using a vertically moving cursor (instantaneous user force feedback). Tracking-force was measured using the Power Grip Manipulandum (www.sensix.fr) and sampled at $1 \mathrm{kHz}$ using a CED Power1401 and Spike2V6 (www.ced.co.uk). The target force followed a ramp-hold-andrelease paradigm in each trial (pause $=3 \mathrm{~s}$; $r a m p=2 \mathrm{~s}$; hold $=3 \mathrm{~s}$; release=instantaneous drop to baseline) at a target force level of $5 \mathrm{~N}$ or $10 \%$ maximum voluntary contraction (Lindberg et al., 2012). A block of six trials at each of the two force levels was repeated three times (for a total of 36 trials, duration: 5'30'). While participants performed the grip-force tracking task, cognitive load was experimentally varied with either (i) a single-task condition (Single; lowest level of cognitive load), corresponding to the basic force-tracking paradigm (36 successive trials) or (ii) a dual-task condition (36x2 trials). In the dual-task condition, two types of visual cues were displayed in pseudo-randomized order. (i) Distractors, consisting of white-filled shapes and displayed for 500ms. Timing and position of appearance was unpredictable. They appeared in each of the four periods, i.e. during REST, before RAMP-onset, during HOLD, and before RELEASE. A maximum of two distractors appeared per trial. Participants had to focus on the tracking task and inhibit saccades toward distractors. (ii) Numbers (from 1 to 9) were displayed (Dual-ADD trials;) for 500ms in pseudo-random positions and with onset-times identical to Dual-DIST trials. Participants had to make a saccade toward the stimulus, mentally sum the numbers of successive trials, and report the sum (after six Dual-task trials) following an auditory cue. Therefore, the Dual-task condition contained trials shared a discrimination component (distractor vs. number), as well as a memory retention component (summed score), imposing a higher cognitive load than the single-task condition. Furthermore, since the addition occurs during Dual-ADD trials only, while memory retention was required in both Dual-task trials, Dual-DIST trials represent intermediate and Dual-ADD trials the highest cognitive load. Trial order: a first batch of 36 successive Single-task trials (5'30'), followed by 72 pseudorandomly intermingled Dual-DIST and Dual-ADD trials (2x 5'30',). For familiarisation, all participants performed a series of 6 consecutive Single-task trials at 10\% Maximal Voluntary Contraction (MVC) before data recording. MVC was assessed using a power grip dynamometer. Participants were instructed prior to the task: to accurately match their grip force to the target force at all times, to ignore (inhibit saccades to) distractors, but to make saccades to relevant visual stimuli (numbers), to mentally sum the successively appearing numbers, and to verbally report the sum after the auditory cue. Thus, peripheral visual on-line information was required to either inhibit (Dual-DIST trial) or to make a saccade (Dual-ADD trial) to a unpredictable and extrafoveal visual stimulus. 


\section{Data analysis}

Visuomotor force-tracking performance was analyzed using MatlabV9.1 (The MathWorks, Inc., Natick, MA, USA). Grip force of all participants was down-sampled to $100 \mathrm{~Hz}$ and smoothed (20ms sliding window using 'root mean square' method; Challis \& Kitney, 1990; Carment et al., 2019). Several performance measures were extracted trial-by-trial and grouped for trial type (36 trials x 3 trial-types) to study the effect of cognitive load on tracking performance (Single-task, Dual-DIST, Dual-ADD) for each participant: precision of tracking error (quantified as the root mean square error [RMSe] between the target and the trackingforce during the ramp and hold periods); timing of force control (quantified by the onset of force production and of force release relative to the respective target, i.e., the time of the positive (production) or negative (release) peak value of the derivative of the tracking force in the interval of $\pm 500 \mathrm{~ms}$ around ramp and release onset); release duration (time taken to abruptly reduce the force from $75 \%$ to $25 \%$ of the target force). A Principal Component Analysis (PCA) was applied to the averaged Single-task force trajectory of each participant, i.e., the averaged grip-force profile across the 36 single-task trials (Teremetz et al., 2014), resulting in a 900x72 data matrix (100 time points/s*N participants).

\section{Statistical analysis}

Statistical analysis was performed using Statistica10 (StatSoft, Inc., USA), involving MannWhitney $U$ tests for assessing group differences in demographic and clinical outcomes. To assess task-related group differences a general linear model repeated measures ANOVA with one GROUP factor (SCZ/ASD/HC) and one within-group factor CONDITION (Singletask/Dual-DIST/Dual-ADD) was used, including Fisher LSD post-hoc test (level of significance: $\mathrm{p}<0.05)$. For the PCA, PC factor scores were obtained for PCs explaining > 5\% of the variability and compared using an ANOVA with one GROUP factor and one withingroup factor of the first three PCs (PC1/PC2/PC3) to identify underlying control strategies between groups. To probe the relation between PC1 and other behavioural and physiological markers of inhibition, Pearson's correlations were used including previously acquired data on short-latency intracortical inhibition (SICI; Kujirai et al., 1993) in HC and patients with SCZ (detailed in Supplementary data). For the ASD group, Spearman's rank-order correlation was used to independently assess relations between the force-tracking error and the following clinical measures: GAF, neurological soft signs (total score, sensori-integration, motor integration and motor coordination subscores), Stroop (interference subscore), WAIS-IV 
('similarities' and 'matrices' sub-scores) and chlorpromazine equivalent (respective correlations for the SCZ group have been previously published, see details in Table 2.; Carment et al., 2019). The level of significance for correlation coefficients was corrected for multiple comparisons (N=9; Benjamini \& Hochberg, 1995).

\section{Results}

\section{Mental addition (Dual-ADD trials)}

There was no difference in performing mental addition between SCZ (81\% \pm 24 correct) and ASD groups $(71 \% \pm 27)$, and between SCZ and HC groups $(88 \% \pm 12)$ (t-test, SCZ vs. ASD: $\mathrm{t}(46)=1.41, \mathrm{p}=0.17$; $\mathrm{SCZ}$ vs. HC: $\mathrm{t}(46)=1.23, \mathrm{p}=0.22)$. However, reporting correct sums in ASD $(71 \% \pm 27)$ was significantly lower compared to $\mathrm{HC}(88 \% \pm 12$, t-test, $\mathrm{t}(46)=2.83, \mathrm{p}=0.007)$.

\section{Precision of force control - force-tracking error}

The ANOVA of force-tracking error (Table 2) showed a significant GROUP effect $(\mathrm{F}(2,68)=8.26, \mathrm{p}<0.001)$, but post-hoc tests revealed that ASD and SCZ groups were not significantly different $(\mathrm{p}=0.09)$, unlike the predicted performance gradient $(A S D>S C Z>C H)$. However, relative to $\mathrm{HC}$ performance, the SCZ group showed a $40 \%$ increase $(\mathrm{p}=0.002)$ and the ASD group a $78 \%$ increase $(\mathrm{p}<0.001)$ in tracking error across conditions.

Concerning modulation of sensorimotor performance by cognitive load, we hypothesized to find group differences according to the $(\mathrm{ASD}>\mathrm{SCZ}>\mathrm{CH})$ gradient. We found a significant effect of CONDITION $(\mathrm{F}(2,68)=34.4, \mathrm{p}<0.001)$, resulting in increased tracking error in DualDIST compared to Single-task trials $(\mathrm{p}<0.001)$, and a further increase of tracking error in DualADD trials $(\mathrm{p}<0.001)$. Moreover, a CONDITION*GROUP interaction was found $(\mathrm{F}(4,136)=2.51, \mathrm{p}=0.04)$. Between group comparisons (Fig. 2) showed that ASD had increased tracking error compared to SCZ only in Dual-ADD trials (Single: $p=0.30$; Dual-DIST: $p=0.21$; Dual-ADD: $\mathrm{p}=0.02$ ). Both patient groups had increased tracking error across conditions compared to control participants (SCZ vs. HC, Single: $p=0.03$; Dual-DIST: $p=0.003$; DualADD: $p<0.001$; ASD vs. HC, Single: p=0.01; Dual-DIST: $p<0.001$; Dual-ADD: $p<0.001$ ). Within group comparison showed that Dual-DIST led to increased tracking error compared to Single-task only in the two patient groups (SCZ: $\mathrm{p}=0.003$; ASD: $\mathrm{p}=0.02, \mathrm{HC}: \mathrm{p}=0.17$ ), whereas Dual-ADD led to increased tracking error compared to Single-task in all three groups (SCZ: p<0.001; ASD: $\mathrm{p}<0.001 ; \mathrm{HC}: \mathrm{p}=0.002)$. 


\section{Timing of force control - force onset and release onset}

The latency of force onset (Table 2) did not differ between groups (ANOVA, $\mathrm{F}(2,68)=1.84$, $\mathrm{p}=0.17$ ) and no interaction effects were found. However, the latency of release onset (Table 2) showed a significant GROUP effect $(\mathrm{F}(2,68)=3.92, \mathrm{p}=0.03)$, with significantly longer onset of force release in the ASD-group from that in the SCZ-group (post-hoc, p=0.01) and HC-group (post-hoc, $\mathrm{p}=0.03$ ), following the partial gradient (ASD>SCZ=HC). SCZ and HC groups had similar latency of release onset $(\mathrm{p}=0.74)$. No other interaction effects were found.

\section{Behavioral measure of motor inhibition - release duration}

Duration of force release was used as an index of motor inhibition. Release duration (Table 2) showed a significant GROUP effect (ANOVA, $\mathrm{F}(2,68)=3.52, \mathrm{p}=0.04$ ), but post-hoc tests revealed that performance in ASD and SCZ groups did not differ $(\mathrm{p}=0.69)$, contrary to our hypothesized gradient ( $\mathrm{ASD}>\mathrm{SCZ}>\mathrm{CH}$ ). Both patient groups showed longer release duration compared to control participants ( $\mathrm{SCZ}$ vs. HC, $\mathrm{p}=0.04$; ASD vs. HC, $\mathrm{p}=0.02$ ). No other interaction effects were found.

\section{PCA results}

The PCA on force trajectories (Fig. 3A) identified different strategies of online visuomotor control. PCA revealed 35 PCs (99.96\% of variation explained) and the first three PCs explained $89 \%$ of the variation $(\mathrm{PC} 1=47 \%$; $\mathrm{PC} 2=34 \%$ and $\mathrm{PC} 3=8 \%$ ). The PC1 loading trajectory (Fig. $3 \mathrm{~B})$ visually resembled the inverse of the average force trajectory and was therefore qualified as an 'inhibition' component. PC2 (Fig. 3C) matched the average force trajectory and was considered a 'production' component, and PC3 (Fig. 3D) resembled the inverse of the first derivative of force and was considered a 'transition' component. The PC factor score for each participant reflects the distance of each participant's data to the origin of each PC (Fig. 3E). The ANOVA of PC factor scores showed no significant GROUP effect $(F(2,68)=0.07, p=0.94)$ and PC-type effect $(\mathrm{F}(2,136)=1.51, \mathrm{p}=0.23)$, but a significant interaction between PC-type and GROUP $(F(4,136)=7.97, \mathrm{p}<0.001)$. ASD and SCZ groups had higher PC1 scores compared to the HC-group (post-hoc $\mathrm{p}<0.001$ and $\mathrm{p}=0.005$, respectively). Moreover, the ASD-group had higher PC1 scores compared to the SCZ-group ( $\mathrm{p}=0.02)$. Therefore, PC1 findings corresponded to the expected impairment gradient pattern (ASD $>\mathrm{SCZ}>\mathrm{HC}$ ). Inversely, we found lower PC2 scores for ASD and SCZ groups compared to HC (SCZ vs. HC, p=0.007; ASD vs. HC, 
$\mathrm{p}<0.001$ ), but no difference between patient groups ( $\mathrm{p}=0.16)$. No significant group difference was found for PC3 scores (all p>0.35).

\section{Inhibition component (PC1) and motor inhibition measures}

Several findings related PC1 to inhibitory mechanisms: First, we found a positive correlation between PC1 loading scores and release duration ( $r=0.36, p=0.002)$ across all participants (Fig. 3F). Second, previously collected neurophysiological data in SCZ and HC showed a negative correlation between short-latency intracortical inhibition (SICI) at rest and PC1 across $\mathrm{HC}$ and patients with SCZ (Pearson's correlation, $r=-0.59$, p<0.001; Supplementary Fig. 1) and this correlation remained significant when performed for each group separately (SCZ: r=-0.54, $\mathrm{p}=0.006 ; \mathrm{HC}: \mathrm{r}=-0.44, \mathrm{p}=0.03)$.

\section{Inhibition component (PC1) and sensorimotor impairments}

To investigate to what degree PC1 could explain tracking performance we performed the ANOVA of force-tracking error using PC1 (inhibition) as a covariate. This explained the GROUP differences in sensorimotor performance $(\mathrm{F}(2,68)=0.76, \mathrm{p}=0.47)$, as well as the CONDITION $^{*}$ GROUP interaction $(\mathrm{F}(4,136)=0.46, \mathrm{p}=0.77)$, as expressed by the no longer significant p-values.

Finally, a multiple linear regression analysis of force-tracking performance between patients with ASD and those with SCZ using the first three PCs as regressors, showed that PC1 and PC3 remained significant predictors of tracking error, but not PC2 (PC1 score: $F(1,46)=29.79$, $\mathrm{p}<0.001$; PC2 score: $\mathrm{F}(1,46)=3.14, \mathrm{p}=0.08$; and PC3 score: $\mathrm{F}(1,46)=20.95, \mathrm{p}<0.001)$. This multiple regression model explained a total of $61 \%$ of force-tracking error in SCZ- and ASDgroups $(\mathrm{F}(3,46)=22.63, \mathrm{p}<0.001, \mathrm{R} 2=0.61)$, and $\mathrm{PC} 1$ alone explained $40 \%(\mathrm{~F}(1,46)=29.79$, $\mathrm{p}<0.001)$.

\section{Tracking performance and clinical scores in ASD}

Force-tracking error correlated negatively with the GAF scale ( $\mathrm{r}=-0.71, \mathrm{p}=0.001)$. No other significant correlation was found with clinical scores, including medication (no outliers found in ASD medicated patients using Hoaglin's method (Hoaglin, Iglewicz, \& Tukey, 1986) for visuomotor performance).

\section{Clinical assessment of sensorimotor performance (NSS)}


We hypothesized that NSS would also follow the (ASD>SCZ $>$ HC) gradient. This was not the case for the total score (Fig. 4; higher scores for SCZ vs. HC: p<0.001; and for ASD vs. HC: $\mathrm{p}<0.001$, but not between patient groups: ASD vs. SCZ: $\mathrm{p}=0.19)$. However, group differences in three sub-scores (sensori-integration, motor-integration and motor-coordination) showed higher sub-scores (greater impairment) in ASD vs. SCZ (all p-values <0.04) and higher subscores in SCZ vs. HC (all p-values <0.05). The fourth sub-score (involuntary-movement) was higher in ASD compared to SCZ ( $\mathrm{p}=0.003)$ and $\mathrm{HC}(\mathrm{p}=0.002)$, but showed no difference between SCZ and HC ( $\mathrm{p}=0.69)$.

\section{Discussion}

In this comparative study between two neurodevelopmental disorders, we provide a first detailed comparison of sensorimotor impairments as probed by a visuomotor grip force task including different levels of cognitive load. The rationale was to identify and differentiate common and/or disorder-specific impairments in patients with autism spectrum disorder and in patients with schizophrenia. Their sensorimotor performance was also assessed relative to that of healthy control participants.

Common impairments were found at lower levels of cognitive load (single-task and Dual-Dist) with ASD and SCZ patients showing similar tracking error and with performance impaired compared to controls, coherent with previous report showing impaired sensorimotor control in ASD (Neely et al., 2019) and in SCZ (Térémetz et al., 2017). Furthermore, release duration, a behavioural marker of motor inhibition, was prolonged in both patient groups compared to controls. These results are coherent with altered sensorimotor control of hand movements in SCZ (Walther \& Mittal, 2016) and in ASD (Whyatt \& Craig, 2013) and they provide indirect evidence for a common inhibitory dysfunction.

Disorder-specific impairments: We hypothesized that the degree of sensorimotor impairment would be disorder-specific, following the gradient (ASD>SCZ>HC). This was generally the case. First, patients with ASD had increased tracking error under condition of highest cognitive load compared to patients with SCZ. Such a dual-task effect has already been reported independently in autistic children during a postural control task (Bucci, Doyen, Contenjean, \& Kaye, 2013) and in patients with schizophrenia (Lin et al., 2015). Here we provide first evidence for a greater dual-task effect in ASD in terms of decreased visuomotor task performance compared to SCZ. Second, the onset of force release was delayed in ASD compared to SCZ and HC. This is likely due to a failure of anticipatory motor control (Wang et al., 2015). Third, 
PCA over the force trajectories revealed PC1, whose temporal shape was supposed to reflect motor inhibition. These PC1 component loadings followed our group difference hypothesis and, when taken as a covariate in the ANOVA, explained group differences in force-tracking error. This is in support of a deficient control of motor inhibition in SCZ (Lindberg et al., 2016) but also, and to a greater extent, in ASD (Schmitt, White, Cook, Sweeney, \& Mosconi, 2018). Finally, at the clinical level, among the NSS scores, three sub-scores followed the gradient, and one sub-score (Involuntary movement) was specifically affected in the ASD-, but not in the SCZ-group. This latter deficit is thought to reflect stereotypical motor behaviour, a core symptom of ASD (Goldman et al., 2009). Furthermore, we found that the degree of sensorimotor impairment, i.e., error in grip-force tracking, was strongly related to the GAF score, which is consistent with several reports indicating an impact on daily functioning related to impaired sensorimotor control in ASD (Jasmin et al., 2009; Travers et al., 2017). Together, these behavioural findings are consistent with sensorimotor impairments in ASD and in SCZ having a common grounding in inhibitory mechanisms, although motor inhibition seems more strongly affected in ASD.

\section{Altered inhibitory component through the neurodevelopmental continuum}

The shape of PC1, resembling the inverse of the force trajectory, was interpreted as reflecting an inhibitory sensorimotor component. Several behavioural and neurophysiological observations are consistent with such an interpretation: (i) release duration, a behavioural marker of inhibitory mechanisms (Lindberg et al., 2012; Teremetz et al., 2014), was correlated to PC1 across participants. (ii) the PC1 loading was negatively correlated to the strength of SICI assessed by TMS in healthy controls and in SCZ patients (Kujirai et al., 1993; see supplementary figure 1). (iii) it has been previously reported that SICI was largely related to $\mathrm{GABA}_{\mathrm{A}}$ mechanisms (Di Lazzaro et al., 2006; Reis et al., 2008) through the recruitment of intracortical inhibitory synapses using a conditioning stimulus (Roshan, Paradiso, \& Chen, 2003; Rothwell, Day, Thompson, \& Kujirai, 2009). This cumulative evidence suggests that PC1 reflects altered inhibition in SCZ and in ASD. It also predicts that patients with ASD should have weaker SICI compared to patients with SCZ. However, no study has to our knowledge directly compared SICI between ASD and SCZ. Studies assessing SICI in ASD are scarce and report heterogenous results (Masuda et al., 2019), no difference (Enticott et al., 2013) or lower SICI (Oberman et al., 2010). Nonetheless, altered cortico-cortical inhibitory mechanisms are supported by functional imaging studies showing atypical activation of inhibition circuitry in ASD (Kana et al., 2007) and in SCZ (Brandt et al., 2015), by magnetic 
resonance spectroscopy indicating that adults with ASD had decreased GABAergic concentration in the sensorimotor cortex (Sapey-Triomphe et al., 2019), and by a recent review reporting that ASD and SCZ shared abnormalities in gene coding for GABAergic receptors (Canitano \& Pallagrosi, 2017). Furthermore, altered pre-pulse inhibition has been linked to GABAergic dysfunction in ASD (Inui, Takeuchi, Sugiyama, Motomura, \& Nishihara, 2018). Thus, while our findings provide supporting evidence for disturbed inhibition as a common factor of impaired online sensorimotor control in both neurodevelopmental disorders, there is so far little physiological evidence for our prediction of more severely affected cortical inhibition in ASD.

\section{Altered anticipatory component in sensorimotor control}

Two temporal measures in the force-tracking task allowed assessment of online anticipatory timing: the onset of force production and of force release. The onset of force release (but not the onset of force production) was delayed in ASD patients compared to SCZ patients and to control participants. This suggests that patients with ASD had a decreased ability to anticipate an abrupt release of force, consistent with previous studies reporting deficient motor anticipation in ASD, whether in infancy (Brisson et al., 2012), childhood (Schmitz et al., 2003) or early adolescence (Schmitt et al., 2018), although this remains uncharacterized in adulthood. An anticipatory dysfunction could be explained by an impaired internal representation or by an inability in handling timing parameters during motor action in ASD (Fabbri-Destro et al., 2008; Forti et al., 2011; Stoit, van Schie, Slaats-Willemse, \& Buitelaar, 2013). Our data suggest that the use of visual feedback might be altered in patients with ASD, leading to difficulties in temporal prediction of force release (Fabbri-Destro et al., 2008; Forti et al., 2011; Stoit et al., 2013; Wang et al., 2015). In contrast, we did not detect any deficits in force onset or release onset in SCZ (nor did Fabbri-Destro et al., 2008; Forti et al., 2011; Stoit et al., 2013), although other studies reported impaired timing/motor prediction using more challenging cues in SCZ patients (Carroll, O’Donnell, Shekhar, \& Hetrick, 2009; Dupin et al., 2018; Térémetz et al., 2017; Voss et al., 2010).

\section{Limitations}

Due to lack of TMS data in the ASD-group, the relation between PC1 and the degree of SICI, observed in controls and in patients with SCZ (Carment et al., 2019), could not be directly established for ASD. However, a recent review also pinpoints altered intra-cortical inhibitory mechanisms in ASD (Masuda et al., 2019). This further highlights the need of 
neurophysiological comparative studies to directly probe a common neurophathological underpinning for motor inhibition within the neuro-developmental continuum. Moreover, to explicitly probe a link within this continuum a quantitative marker would be needed, such as genetic load. Finally, we only investigated adult patients with ASD: replication in children would be indicated.

\section{Conclusions}

Using visuomotor control of grip force, we found common and distinct sensorimotor impairments in ASD and in SCZ. Both patient groups showed impaired motor inhibition (extracted by PCA), which largely explained group differences in force-tracking performance. This inhibition component was most severely impaired in ASD (ASD>SCZ>HC), as was tracking performance during high cognitive load. These behavioural results point to a common impairment in motor inhibition across these two neurodevelopmental disorders, however, patients with ASD were more severely affected, in line with early dysregulated maturation of neural inhibition. Furthermore, our findings suggest that some motor deficits, such as impaired feedback-dependent motor anticipation (prediction) and stereotypical motor behaviour, might be specific to ASD and likely pinpoint core symptoms of this disease. This highlights the need for further study of sensorimotor impairment through the neurodevelopmental continuum, by combining behavioural and neurophysiological techniques.

\section{Conflict of interest}

The authors declare no competing financial interests.

\section{References}

American Psychiatric Association. (2013). Diagnostic and Statistical Manual of Mental Disorders (Fifth Edition). https://doi.org/10.1176/appi.books.9780890425596

Bachmann, S., Degen, C., Geider, F. J., \& Schröder, J. (2014). Neurological Soft Signs in the Clinical Course of Schizophrenia : Results of a Meta-Analysis. Frontiers in Psychiatry, 5. https://doi.org/10.3389/fpsyt.2014.00185 
Baumer, N., \& Spence, S. J. (2018). Evaluation and Management of the Child With Autism Spectrum Disorder. Continuum (Minneapolis, Minn.), 24(1, Child Neurology), 248- 275. https://doi.org/10.1212/CON.0000000000000578

Benjamini, Y., \& Hochberg, Y. (1995). Controlling the False Discovery Rate : A Practical and Powerful Approach to Multiple Testing. Journal of the Royal Statistical Society. Series B (Methodological), 57(1), 289- 300. https://doi.org/10.2307/2346101

Biswas, P., Malhotra, S., Malhotra, A., \& Gupta, N. (2007). Comparative study of neurological soft signs in schizophrenia with onset in childhood, adolescence and adulthood. Acta Psychiatrica Scandinavica, 115(4), 295-303. https://doi.org/10.1111/j.16000447.2006.00901.x

Bölte, S., Rudolf, L., \& Poustka, F. (2002). The cognitive structure of higher functioning autism and schizophrenia : A comparative study. Comprehensive Psychiatry, 43(4), 325- 330.

Bowie, C. R., Reichenberg, A., Patterson, T. L., Heaton, R. K., \& Harvey, P. D. (2006). Determinants of real-world functional performance in schizophrenia subjects: Correlations with cognition, functional capacity, and symptoms. The American Journal of Psychiatry, 163(3), 418- 425. https://doi.org/10.1176/appi.ajp.163.3.418

Brandt, C. L., Kaufmann, T., Agartz, I., Hugdahl, K., Jensen, J., Ueland, T., ... Westlye, L. T. (2015). Cognitive Effort and Schizophrenia Modulate Large-Scale Functional Brain Connectivity. Schizophrenia Bulletin, 41(6), 1360-1369. https://doi.org/10.1093/schbul/sbv013

Brisson, J., Warreyn, P., Serres, J., Foussier, S., \& Adrien, J.-L. (2012). Motor anticipation failure in infants with autism: A retrospective analysis of feeding situations. Autism : the international journal of research and practice, 16, 420-429. https://doi.org/10.1177/1362361311423385 
Bucci, M. P., Doyen, C., Contenjean, Y., \& Kaye, K. (2013). The Effect of Performing a Dual Task on Postural Control in Children with Autism. ISRN Neuroscience, 2013. https://doi.org/10.1155/2013/796174

Caldani, S., Amado, I., Bendjemaa, N., Vialatte, F., Mam-Lam-Fook, C., Gaillard, R., ... Pia Bucci, M. (2017). Oculomotricity and Neurological Soft Signs: Can we refine the endophenotype? A study in subjects belonging to the spectrum of schizophrenia. Psychiatry Research, 256, 490- 497. https://doi.org/10.1016/j.psychres.2017.06.013

Canitano, R., \& Pallagrosi, M. (2017). Autism Spectrum Disorders and Schizophrenia Spectrum Disorders : Excitation/Inhibition Imbalance and Developmental Trajectories. Frontiers in Psychiatry, 8. https://doi.org/10.3389/fpsyt.2017.00069

Carment, L., Dupin, L., Guedj, L., Térémetz, M., Krebs, M.-O., Cuenca, M., ... Lindberg, P. G. (2019). Impaired attentional modulation of sensorimotor control and cortical excitability in schizophrenia. Brain: A Journal of Neurology. https://doi.org/10.1093/brain/awz127

Carroll, C. A., O'Donnell, B. F., Shekhar, A., \& Hetrick, W. P. (2009). Timing dysfunctions in schizophrenia as measured by a repetitive finger tapping task. Brain and Cognition, 71(3), 345- 353. https://doi.org/10.1016/j.bandc.2009.06.009

Challis, R.E., Kitney, R.I. (1990) Biomedical signal processing (in four parts). Med. Biol. Eng. Comput. 28, 509-524. https://doi.org/10.1007/BF02442601

Clark, G. M., \& Lum, J. A. G. (2017). Procedural learning in Parkinson's disease, specific language impairment, dyslexia, schizophrenia, developmental coordination disorder, and autism spectrum disorders : A second-order meta-analysis. Brain and Cognition, 117, 41 - 48. https://doi.org/10.1016/j.bandc.2017.07.004 
Di Lazzaro, V., Pilato, F., Dileone, M., Ranieri, F., Ricci, V., Profice, P., ... Ziemann, U. (2006). GABAA receptor subtype specific enhancement of inhibition in human motor cortex. $\begin{array}{llll}\text { The Journal of } & \text { Physiology, } & \text { 575(Pt } & 321 \text { ), }\end{array}$ https://doi.org/10.1113/jphysiol.2006.114694

Dupin, L., Carment, L., Guedj, L., Cuenca, M., Krebs, M.-O., Maier, M. A., ... Lindberg, P. G. (2018). Predictive Modulation of Corticospinal Excitability and Implicit Encoding of Movement Probability in Schizophrenia. Schizophrenia Bulletin. https://doi.org/10.1093/schbul/sby186

Enticott, P. G., Kennedy, H. A., Rinehart, N. J., Tonge, B. J., Bradshaw, J. L., \& Fitzgerald, P. B. (2013). GABAergic activity in autism spectrum disorders : An investigation of cortical inhibition via transcranial magnetic stimulation. Neuropharmacology, 68, 202- 209. https://doi.org/10.1016/j.neuropharm.2012.06.017

Fabbri-Destro, M., Cattaneo, L., Boria, S., \& Rizzolatti, G. (2008). Planning actions in Autism. Experimental brain research. Experimentelle Hirnforschung. Expérimentation cérébrale, 192, 521 - 525. https://doi.org/10.1007/s00221-008-1578-3

Forti, S., Valli, A., Perego, P., Nobile, M., Crippa, A., \& Molteni, M. (2011). Motor planning and control in autism. A kinematic analysis of preschool children. Research in Autism Spectrum Disorders, 5(2), 834- 842. https://doi.org/10.1016/j.rasd.2010.09.013

Geschwind, D. H., \& Levitt, P. (2007). Autism spectrum disorders: Developmental disconnection syndromes. Current Opinion in Neurobiology, 17(1), 103-111. https://doi.org/10.1016/j.conb.2007.01.009

Goldman, S., Wang, C., Salgado, M. W., Greene, P. E., Kim, M., \& Rapin, I. (2009). Motor stereotypies in children with autism and other developmental disorders. 
Developmental Medicine and Child Neurology, 51(1), 30-38. https://doi.org/10.1111/j.1469-8749.2008.03178.x

Gomez-Pilar, J., Lubeiro, A., Poza, J., Hornero, R., Ayuso, M., Valcárcel, C., ... Molina, V. (2017). Functional EEG network analysis in schizophrenia : Evidence of larger segregation and deficit of modulation. Progress in Neuro-Psychopharmacology \& Biological Psychiatry, 76, 116- 123. https://doi.org/10.1016/j.pnpbp.2017.03.004

Gourion, D., Goldberger, C., Olie, J. P., Lôo, H., \& Krebs, M. O. (2004). Neurological and morphological anomalies and the genetic liability to schizophrenia : A composite phenotype. Schizophrenia Research, 67(1), 23- 31.

Grégoire, J., \& Wierzbicki, C. (2009). Comparison of four short forms of the Wechsler Adult Intelligence Scale - third edition (WAIS-III). Revue européenne de psychologie appliquée, (59), 17- 24.

Halayem, S., Bouden, A., Halayem, M. B., Tabbane, K., Amado, I., \& Krebs, M. O. (2010). [Neurological soft signs in pervasive developmental disorders]. L'Encephale, 36(4), 307- 313. https://doi.org/10.1016/j.encep.2009.12.012

Hirjak, D., Wolf, R. C., Koch, S. C., Mehl, L., Kelbel, J. K., Kubera, K. M., ... Thomann, P. A. (2014). Neurological Abnormalities in Recent-Onset Schizophrenia and Asperger-Syndrome. Frontiers in Psychiatry, 5. https://doi.org/10.3389/fpsyt.2014.00091

Hoaglin, D. C., Iglewicz, B., \& Tukey, J. W. (1986). Performance of Some Resistant Rules for Outlier Labeling. Journal of the American Statistical Association, 81(396), 991-999. https://doi.org/10.1080/01621459.1986.10478363

Insel, T. R. (2010). Rethinking schizophrenia. Nature, 468(7321), 187-193. https://doi.org/10.1038/nature09552 
Inui, K., Takeuchi, N., Sugiyama, S., Motomura, E., \& Nishihara, M. (2018). GABAergic mechanisms involved in the prepulse inhibition of auditory evoked cortical responses in humans. PloS One, 13(1), e0190481. https://doi.org/10.1371/journal.pone.0190481 Jansiewicz, E. M., Goldberg, M. C., Newschaffer, C. J., Denckla, M. B., Landa, R., \& Mostofsky, S. H. (2006). Motor signs distinguish children with high functioning autism and Asperger's syndrome from controls. Journal of Autism and Developmental Disorders, 36(5), 613- 621. https://doi.org/10.1007/s10803-006-0109-y

Jasmin, E., Couture, M., McKinley, P., Reid, G., Fombonne, E., \& Gisel, E. (2009). Sensori-motor and daily living skills of preschool children with autism spectrum disorders. Journal of Autism and Developmental Disorders, 39(2), 231-241. https://doi.org/10.1007/s10803-008-0617-z

Jones, S. H., Thornicroft, G., Coffey, M., \& Dunn, G. (1995). A brief mental health outcome scale-reliability and validity of the Global Assessment of Functioning (GAF). The British Journal of Psychiatry: The Journal of Mental Science, 166(5), 654- 659.

Kana, R. K., Keller, T. A., Minshew, N. J., \& Just, M. A. (2007). Inhibitory control in highfunctioning autism: Decreased activation and underconnectivity in inhibition networks. Biological Psychiatry, 62(3), 198-206. https://doi.org/10.1016/j.biopsych.2006.08.004

Kay, S. R., Fiszbein, A., \& Opler, L. A. (1987). The positive and negative syndrome scale (PANSS) for schizophrenia. Schizophrenia Bulletin, 13(2), 261- 276.

Krebs, M. O., Gut-Fayand, A., Bourdel, M., Dischamp, J., \& Olié, J. (2000). Validation and factorial structure of a standardized neurological examination assessing neurological soft signs in schizophrenia. Schizophrenia Research, 45(3), 245- 260. 
Kujirai, T., Caramia, M. D., Rothwell, J. C., Day, B. L., Thompson, P. D., Ferbert, A., ... Marsden, C. D. (1993). Corticocortical inhibition in human motor cortex. The Journal of Physiology, 471, 501- 519.

Lin, K., Wu, Y., Chen, I. -chen, Tsai, P., Wu, C., \& Chen, C. (2015). Dual-task performance involving hand dexterity and cognitive tasks and daily functioning in people with schizophrenia : A pilot study. The American Journal of Occupational Therapy: Official Publication of the American Occupational Therapy Association, 69(3), 6903250020p17. https://doi.org/10.5014/ajot.2014.014738

Lindberg, P. G., Roche, N., Robertson, J., Roby-Brami, A., Bussel, B., \& Maier, M. A. (2012). Affected and unaffected quantitative aspects of grip force control in hemiparetic patients after stroke. Brain Research, 1452, 96-107. https://doi.org/10.1016/j.brainres.2012.03.007

Lindberg, P. G., Térémetz, M., Charron, S., Kebir, O., Saby, A., Bendjemaa, N., ... Amado, I. (2016). Altered cortical processing of motor inhibition in schizophrenia. Cortex; $a$ Journal Devoted to the Study of the Nervous System and Behavior, 85, 1-12. https://doi.org/10.1016/j.cortex.2016.09.019

Lord, C., Rutter, M., \& Le Couteur, A. (1994). Autism Diagnostic Interview-Revised : A revised version of a diagnostic interview for caregivers of individuals with possible pervasive developmental disorders. Journal of Autism and Developmental Disorders, 24(5), $659-685$.

Martineau, J., Schmitz, C., Assaiante, C., Blanc, R., \& Barthélémy, C. (2004). Impairment of a cortical event-related desynchronisation during a bimanual load-lifting task in children with autistic disorder. Neuroscience Letters, 367(3), 298-303. https://doi.org/10.1016/j.neulet.2004.06.018 
Martinez, G., Alexandre, C., Mam-Lam-Fook, C., Bendjemaa, N., Gaillard, R., Garel, P., ... Krebs, M.-O. (2017). Phenotypic continuum between autism and schizophrenia : Evidence from the Movie for the Assessment of Social Cognition (MASC). Schizophrenia Research, 185, 161- 166. https://doi.org/10.1016/j.schres.2017.01.012

Martinez, G., Mosconi, E., Daban-Huard, C., Parellada, M., Fananas, L., Gaillard, R., ... Amado, I. (2019). "A circle and a triangle dancing together" : Alteration of social cognition in schizophrenia compared to autism spectrum disorders. Schizophrenia Research. https://doi.org/10.1016/j.schres.2019.05.043

Masuda, F., Nakajima, S., Miyazaki, T., Yoshida, K., Tsugawa, S., Wada, M., ... Noda, Y. (2019). Motor cortex excitability and inhibitory imbalance in autism spectrum disorder assessed with transcranial magnetic stimulation : A systematic review. Translational Psychiatry, 9(1), 110. https://doi.org/10.1038/s41398-019-0444-3

Millan, M. J., Andrieux, A., Bartzokis, G., Cadenhead, K., Dazzan, P., Fusar-Poli, P., ... Weinberger, D. (2016). Altering the course of schizophrenia: Progress and perspectives. Nature Reviews. Drug Discovery, 15(7), 485-515. https://doi.org/10.1038/nrd.2016.28

Mosconi, M. W., \& Sweeney, J. A. (2015). Sensorimotor dysfunctions as primary features of autism spectrum disorders. Science China. Life Sciences, 58(10), 1016-1023. https://doi.org/10.1007/s11427-015-4894-4

Munetz, M. R., \& Benjamin, S. (1988). How to examine patients using the Abnormal Involuntary Movement Scale. Hospital \& Community Psychiatry, 39(11), 1172- 1177.

Neely, K. A., Mohanty, S., Schmitt, L. M., Wang, Z., Sweeney, J. A., \& Mosconi, M. W. (2019). Motor Memory Deficits Contribute to Motor Impairments in Autism Spectrum 
Disorder. Journal of Autism and Developmental Disorders, 49(7), 2675-2684. https://doi.org/10.1007/s10803-016-2806-5

Noda, Y., Barr, M. S., Zomorrodi, R., Cash, R. F. H., Farzan, F., Rajji, T. K., ... Blumberger, D. M. (2017). Evaluation of short interval cortical inhibition and intracortical facilitation from the dorsolateral prefrontal cortex in patients with schizophrenia. Scientific Reports, 7(1), 17106. https://doi.org/10.1038/s41598-017-17052-3

Oberman, L., Ifert-Miller, F., Najib, U., Bashir, S., Woollacott, I., Gonzalez-Heydrich, J., ... Pascual-Leone, A. (2010). Transcranial Magnetic Stimulation Provides Means to Assess Cortical Plasticity and Excitability in Humans with Fragile X Syndrome and Autism Spectrum Disorder. Frontiers in Synaptic Neuroscience, 2. https://doi.org/10.3389/fnsyn.2010.00026

Oberman, L. M., Pascual-Leone, A., \& Rotenberg, A. (2014). Modulation of corticospinal excitability by transcranial magnetic stimulation in children and adolescents with autism spectrum disorder. Frontiers in Human Neuroscience, 8. https://doi.org/10.3389/fnhum.2014.00627

Overall, J. E., \& Gorham, D. R. (1962). The Brief Psychiatric Rating Scale. Psychological Reports, 10(3), 799- 812. https://doi.org/10.2466/pr0.1962.10.3.799

Radhu, N., de Jesus, D. R., Ravindran, L. N., Zanjani, A., Fitzgerald, P. B., \& Daskalakis, Z. J. (2013). A meta-analysis of cortical inhibition and excitability using transcranial magnetic stimulation in psychiatric disorders. Clinical Neurophysiology: Official Journal of the International Federation of Clinical Neurophysiology, 124(7), 1309-1320. https://doi.org/10.1016/j.clinph.2013.01.014

Reis, J., Swayne, O. B., Vandermeeren, Y., Camus, M., Dimyan, M. A., Harris-Love, M., ... Cohen, L. G. (2008). Contribution of transcranial magnetic stimulation to the understanding of 
cortical mechanisms involved in motor control. The Journal of Physiology, 586(Pt 2), 325- 351. https://doi.org/10.1113/jphysiol.2007.144824

Roshan, L., Paradiso, G. O., \& Chen, R. (2003). Two phases of short-interval intracortical inhibition. Experimental Brain Research, 151(3), 330-337. https://doi.org/10.1007/s00221-003-1502-9

Rothwell, J. C., Day, B. L., Thompson, P. D., \& Kujirai, T. (2009). Short latency intracortical inhibition: One of the most popular tools in human motor neurophysiology. The $\begin{array}{llll}\text { Journal of } & \text { Physiology, }\end{array}$ https://doi.org/10.1113/jphysiol.2008.162461

Sailer, U., Eggert, T., Strassnig, M., Riedel, M., \& Straube, A. (2007). Predictive eye and hand movements are differentially affected by schizophrenia. European Archives of

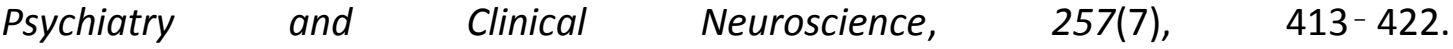
https://doi.org/10.1007/s00406-007-0749-8

Sapey-Triomphe, L.-A., Lamberton, F., Sonié, S., Mattout, J., \& Schmitz, C. (2019). Tactile hypersensitivity and GABA concentration in the sensorimotor cortex of adults with autism. Autism Research: Official Journal of the International Society for Autism Research, 12(4), 562- 575. https://doi.org/10.1002/aur.2073

Schmitt, L. M., White, S. P., Cook, E. H., Sweeney, J. A., \& Mosconi, M. W. (2018). Cognitive mechanisms of inhibitory control deficits in autism spectrum disorder. Journal of Child Psychology and Psychiatry, and Allied Disciplines, 59(5), 586-595. https://doi.org/10.1111/jcpp.12837

Schmitz, C., Martineau, J., Barthélémy, C., \& Assaiante, C. (2003). Motor control and children with autism: Deficit of anticipatory function? Neuroscience letters, 348, 17- 20. https://doi.org/10.1016/S0304-3940(03)00644-X 
Simpson, G. M., \& Angus, J. W. (1970). A rating scale for extrapyramidal side effects. Acta Psychiatrica Scandinavica. Supplementum, 212, 11- 19.

St Pourcain, B., Robinson, E. B., Anttila, V., Sullivan, B. B., Maller, J., Golding, J., ... Davey Smith, G. (2017). ASD and schizophrenia show distinct developmental profiles in common genetic overlap with population-based social communication difficulties. Molecular Psychiatry, 23, 263.

Stoit, A. M. B., van Schie, H. T., Slaats-Willemse, D. I. E., \& Buitelaar, J. K. (2013). Grasping motor impairments in autism: Not action planning but movement execution is deficient. Journal of Autism and Developmental Disorders, 43(12), 2793-2806. https://doi.org/10.1007/s10803-013-1825-8

Stroop, R. J. (1935). Studies of interference in serial verbal reactions. Journal of Experimental Psychology, (18), 643-662.

Teremetz, M., Amado, I., Bendjemaa, N., Krebs, M.-O., Lindberg, P. G., \& Maier, M. A. (2014). Deficient grip force control in schizophrenia : Behavioral and modeling evidence for altered motor inhibition and motor noise. PloS One, 9(11), e111853. https://doi.org/10.1371/journal.pone.0111853

Térémetz, M., Carment, L., Brénugat-Herne, L., Croca, M., Bleton, J.-P., Krebs, M.-O., ... Lindberg, P. G. (2017). Manual Dexterity in Schizophrenia-A Neglected Clinical Marker? Frontiers in Psychiatry, 8, 120. https://doi.org/10.3389/fpsyt.2017.00120

Travers, B. G., Bigler, E. D., Duffield, T. C., Prigge, M. D. B., Froehlich, A. L., Lange, N., ... Lainhart, J. E. (2017). Longitudinal development of manual motor ability in autism spectrum disorder from childhood to mid-adulthood relates to adaptive daily living skills. Developmental Science, 20(4). https://doi.org/10.1111/desc.12401 
Travers, B. G., Bigler, E. D., Tromp, D. P. M., Adluru, N., Destiche, D., Samsin, D., ... Lainhart, J. E. (2015). Brainstem White Matter Predicts Individual Differences in Manual Motor Difficulties and Symptom Severity in Autism. Journal of Autism and Developmental Disorders, 45(9), 3030 - 3040. https://doi.org/10.1007/s10803-015-2467-9

Voss, M., Moore, J., Hauser, M., Gallinat, J., Heinz, A., \& Haggard, P. (2010). Altered awareness of action in schizophrenia : A specific deficit in predicting action consequences. Brain, 133(10), 3104- 3112. https://doi.org/10.1093/brain/awq152

Walther, S., \& Mittal, V. A. (2016). Why We Should Take a Closer Look at Gestures. Schizophrenia Bulletin, 42(2), 259- 261. https://doi.org/10.1093/schbul/sbv229

Walther, S., \& Strik, W. (2012). Motor symptoms and schizophrenia. Neuropsychobiology, 66(2), 77- 92. https://doi.org/10.1159/000339456

Wang, Z., Magnon, G. C., White, S. P., Greene, R. K., Vaillancourt, D. E., \& Mosconi, M. W. (2015). Individuals with autism spectrum disorder show abnormalities during initial and subsequent phases of precision gripping. Journal of Neurophysiology, 113(7), 1989- 2001. https://doi.org/10.1152/jn.00661.2014

Whyatt, C., \& Craig, C. (2013). Sensory-motor problems in Autism. Frontiers in Integrative Neuroscience, 7. https://doi.org/10.3389/fnint.2013.00051 


\begin{tabular}{|c|c|c|c|}
\hline & $\begin{array}{c}\text { ASD } \\
\text { group } \\
(\text { Mean } \pm \text { SD }) \\
\end{array}$ & $\begin{array}{c}\mathbf{S C Z} \\
\text { group } \\
\text { (Mean } \pm \mathrm{SD})\end{array}$ & $\begin{array}{c}\text { HC } \\
\text { group } \\
(\text { Mean } \pm \text { SD) }\end{array}$ \\
\hline \multicolumn{4}{|l|}{ Demographic data } \\
\hline $\begin{array}{r}\text { Age } \\
\text { (years) }\end{array}$ & $29 \pm 7$ & $31 \pm 9$ & $30 \pm 7$ \\
\hline Gender & $6 \mathrm{~F} / 18 \mathrm{M}$ & $6 \mathrm{~F} / 18 \mathrm{M}$ & $6 \mathrm{~F} / 18 \mathrm{M}$ \\
\hline \multicolumn{4}{|l|}{ Clinical data } \\
\hline $\begin{array}{r}\text { Medicated } \\
(\mathrm{M} / \mathrm{NM})\end{array}$ & $6 \mathrm{M} / 18 \mathrm{NM}$ & $24 \mathrm{M}$ & - \\
\hline $\begin{array}{r}\text { BPRS } \\
{[24-68]}\end{array}$ & $36 \pm 9$ & $44 \pm 6^{*}$ & - \\
\hline $\begin{array}{r}\text { GAF } \\
{[0-100]}\end{array}$ & $63 \pm 12$ & $57 \pm 13$ & - \\
\hline $\begin{array}{r}\text { SAS } \\
{[0-44]}\end{array}$ & $3 \pm 4$ & $3 \pm 3$ & $1.6 \pm 1.1$ \\
\hline $\begin{array}{c}\text { AIMS } \\
{[0-40]}\end{array}$ & $2 \pm 4$ & $1 \pm 2$ & $0.3 \pm 0.4$ \\
\hline \multicolumn{4}{|c|}{ Neuropsychological scores } \\
\hline $\begin{array}{r}\text { WAIS } \\
\text { Similarities [0-19] }\end{array}$ & $13.2 \pm 3.5$ & $12.2 \pm 2.9$ & $14.6 \pm 2.1$ \\
\hline $\begin{array}{r}\text { WAIS } \\
\text { Matrix [0-19] }\end{array}$ & $10.5 \pm 2.9$ & $11.5 \pm 3.1$ & $12.3 \pm 2.4$ \\
\hline $\begin{array}{r}\text { STROOP } \\
\text { Interference }(\mathrm{s})\end{array}$ & $124.5 \pm 38.9$ & $112 \pm 33.6$ & $91.4 \pm 29.6 * *$ \\
\hline $\begin{array}{r}\text { STROOP } \\
\text { Interference (error) } \\
\end{array}$ & $1.6 \pm 1.8$ & $1.9 \pm 1.6$ & $0.8 \pm 1.1 *$ \\
\hline \multicolumn{4}{|c|}{ Neurological soft signs (NSS) } \\
\hline $\begin{array}{r}\text { Total score } \\
{[0-105]}\end{array}$ & $16.1 \pm 5.8$ & $13.4 \pm 5.6$ & $7.7 \pm 3.5 * * *$ \\
\hline $\begin{array}{r}\text { Sensory integration } \\
{[0-15]}\end{array}$ & $3.1 \pm 2.5$ & $1.8 \pm 1.6^{* *}$ & $0.9 \pm 1.1 * * *$ \\
\hline $\begin{array}{r}\text { Motor coordination } \\
{[0-21]}\end{array}$ & $7.6 \pm 3.6$ & $5.5 \pm 2.4$ & $3.7 \pm 2.1 * * *$ \\
\hline $\begin{array}{r}\text { Motor integration } \\
{[0-18]}\end{array}$ & $3.2 \pm 2.6$ & $1.1 \pm 1.1 * *$ & $0.5 \pm 0.7 * * *$ \\
\hline $\begin{array}{r}\text { Involuntary movement } \\
{[0-6]}\end{array}$ & $1.1 \pm 1.5$ & $0.1 \pm 0.3^{* *}$ & $0.1 \pm 0.3^{* *}$ \\
\hline
\end{tabular}

Table 1. Clinical and demographic data.

Clinical and demographic data (mean \pm SD) for patients with autism spectrum disorder (ASD), patients with schizophrenia (SCZ) and healthy controls (HC). Patients were assessed using the brief psychiatric rating scale (BPRS), global assessment of functioning (GAF), Simpson Angus Extra-Pyramidal Scale (SAS), Abnormal Involuntary Movements Scale (AIMS), and neurological soft signs (NSS). Executive function was assessed by the WAIS scores 'Similarities' and 'Matrix'. 'Interference' is a sub-score of the Stroop color naming test. There was no difference in the demographic data between groups. Group differences compared to 
ASD group for clinical data were tested with Mann-Whitney $U$ tests and are indicated as follows: $*=p<0.05 ; * *=p<0.01, * * *=p<0.001$. Note: significant group differences between SCZ and HC groups (not indicated) were as follows: Neuropsychological scores - Similarities (WAIS), p=0.002; STROOP Interference (s), p=0.02; STROOP Interference (errors), p=0.004; Neurological soft signs (NSS) - total score and sensori integration, motor coordination and motor integration sub-scores, all p-values $<0.05$.

\begin{tabular}{|c|c|c|c|c|c|c|c|c|c|}
\hline & \multicolumn{3}{|c|}{$\begin{array}{c}\text { ASD group } \\
(\text { Mean } \pm S D)\end{array}$} & \multicolumn{3}{|c|}{$\underset{(\text { Mean } \pm \text { SD })}{\text { SCZ group }}$} & \multicolumn{3}{|c|}{$\begin{array}{c}\text { HC group } \\
(\text { Mean } \pm \text { SD })\end{array}$} \\
\hline \multicolumn{10}{|l|}{ Force control } \\
\hline & $\begin{array}{c}\text { Single } \\
\text { task }\end{array}$ & $\begin{array}{l}\text { Dual } \\
\text { DIST }\end{array}$ & $\begin{array}{l}\text { Dual } \\
\text { ADD }\end{array}$ & $\begin{array}{c}\text { Single } \\
\text { task }\end{array}$ & $\begin{array}{l}\text { Dual } \\
\text { DIST }\end{array}$ & $\begin{array}{l}\text { Dual } \\
\text { ADD }\end{array}$ & $\begin{array}{c}\text { Single } \\
\text { task }\end{array}$ & $\begin{array}{l}\text { Dual } \\
\text { DIST }\end{array}$ & $\begin{array}{l}\text { Dual } \\
\text { ADD }\end{array}$ \\
\hline $\begin{array}{r}\text { Tracking error } \\
\text { (RMSe) }\end{array}$ & $\begin{array}{c}0.14 \\
\pm 0.06\end{array}$ & $\begin{array}{c}0.17 \\
\pm 0.09\end{array}$ & $\begin{array}{c}0.22 \\
\pm 0.14\end{array}$ & $\begin{array}{c}0.12 \\
\pm 0.05\end{array}$ & $\begin{array}{c}0.15 \\
\pm 0.07\end{array}$ & $\begin{array}{c}0.17 \\
\pm 0.09\end{array}$ & $\begin{array}{c}0.09 \\
\pm 0.03\end{array}$ & $\begin{array}{c}0.10 \\
\pm 0.04\end{array}$ & $\begin{array}{c}0.13 \\
\pm 0.05\end{array}$ \\
\hline $\begin{array}{r}\text { Release duration } \\
(\mathrm{ms})\end{array}$ & $\begin{array}{l}158 \\
\pm 34\end{array}$ & $\begin{array}{r}170 \\
\pm 59\end{array}$ & $\begin{array}{l}169 \\
\pm 60\end{array}$ & $\begin{array}{l}166 \\
\pm 46\end{array}$ & $\begin{array}{l}171 \\
\pm 61\end{array}$ & $\begin{array}{l}179 \\
\pm 89\end{array}$ & $\begin{array}{l}148 \\
\pm 30\end{array}$ & $\begin{array}{l}142 \\
\pm 45\end{array}$ & $\begin{array}{l}145 \\
\pm 44\end{array}$ \\
\hline $\begin{array}{l}\text { Force onset } \\
\text { latency }(\mathrm{ms})\end{array}$ & $\begin{array}{l}106 \\
\pm 93\end{array}$ & $\begin{array}{c}89 \\
\pm 87\end{array}$ & $\begin{array}{l}111 \\
\pm 93\end{array}$ & $\begin{array}{l}118 \\
\pm 22\end{array}$ & $\begin{array}{l}119 \\
\pm 38\end{array}$ & $\begin{array}{c}150 \\
\pm 120\end{array}$ & $\begin{array}{l}115 \\
\pm 29\end{array}$ & $\begin{array}{l}120 \\
\pm 46\end{array}$ & $\begin{array}{l}132 \\
\pm 50\end{array}$ \\
\hline $\begin{array}{r}\text { Force release } \\
\text { latency }(\mathrm{ms})\end{array}$ & $\begin{array}{l}127 \\
\pm 55\end{array}$ & $\begin{array}{l}120 \\
\pm 67 \\
\end{array}$ & $\begin{array}{l}139 \\
\pm 65 \\
\end{array}$ & $\begin{array}{l}165 \\
\pm 50\end{array}$ & $\begin{array}{l}166 \\
\pm 62\end{array}$ & $\begin{array}{l}171 \\
\pm 59 \\
\end{array}$ & $\begin{array}{l}161 \\
\pm 43\end{array}$ & $\begin{array}{l}155 \\
\pm 47 \\
\end{array}$ & $\begin{array}{l}160 \\
\pm 46\end{array}$ \\
\hline \multicolumn{10}{|l|}{ PCA } \\
\hline PC1 loading & \multicolumn{3}{|c|}{$7.6 \pm 17.5$} & \multicolumn{3}{|c|}{$1.3 \pm 12.3$} & \multicolumn{3}{|c|}{$-8.8 \pm 7.7$} \\
\hline PC2 loading & \multicolumn{3}{|c|}{$-3 \pm 10.6$} & \multicolumn{3}{|c|}{$2 \pm 11.3$} & \multicolumn{3}{|c|}{$8.6 \pm 6.5$} \\
\hline PC3 loading & \multicolumn{3}{|c|}{$-2.4 \pm 12.8$} & \multicolumn{3}{|c|}{$0.4 \pm 5.2$} & \multicolumn{3}{|c|}{$1.9 \pm 5.3$} \\
\hline
\end{tabular}

Table 2. Visuomotor measures for the three groups: patients with autism spectrum disorder (ASD), patients with schizophrenia (SCZ) and healthy control participants (HC).

Force control: main measures (mean $\pm \mathrm{SD}$ ) of performance in force control are detailed for all groups in (i) the Single-task tracking condition and the two Dual-task conditions with (ii) Dualtask distraction trials (Dual-DIST) and (iii) Dual-task addition trials (Dual-ADD). Principal component analysis (PCA): loading score $($ mean $\pm \mathrm{SD})$ of the first three components. 


\section{Figures legends FIG. 1}

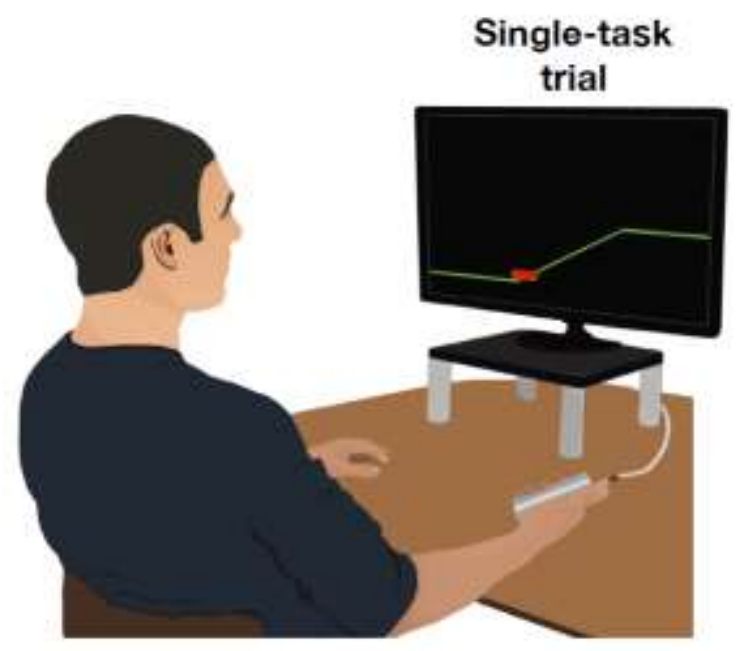

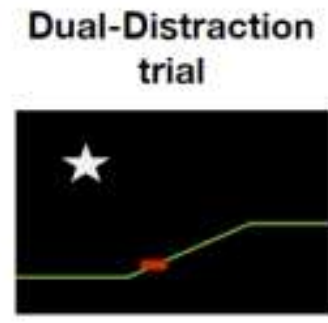

Subjects were instructed to inhibit a saccades toward a briefly and randomly appearing shape

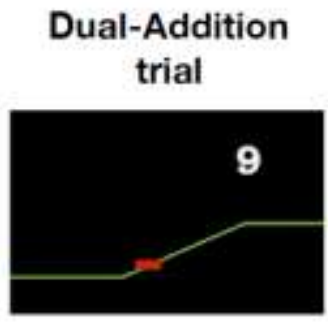

Subjects were instructed to make a saccade toward a briefly and randomly appearing number

Fig 1. Visuomotor grip force-tracking setup and conditions.

Setup for the visuomotor task: participants were seated in front of a 22" computer screen, set at eye level at a distance of $60 \mathrm{~cm}$. The screen displayed the visuomotor force-tracking tasks. Grip force was displayed as a red cursor moving vertically and in real-time as a function of the exerted grip force. The target force was displayed as a right-to-left scrolling coloured line. A trial consisted of a single ramp-hold-and-release sequence. Trials with different cognitive load were presented pseudo-randomly: (i) Single-task trial (Single): grip force-tracking; (ii) Dualtask distraction trial (Dual-DIST): during force-tracking, distractors, consisting of white-filled shapes (square, star, triangle, $2 \times 2 \mathrm{~cm}$ ), were randomly displayed for $500 \mathrm{~ms}$ in the four periods at specific times (1500ms into REST; 380ms before RAMP onset; $1500 \mathrm{~ms}$ into hold; and 380ms before RELEASE).; (iii) Dual-task addition trial (Dual-ADD): while participants performed the force-tracking task, numbers (from 1 to $9,2 \times 2 \mathrm{~cm}$ ) were displayed for $500 \mathrm{~ms}$ with onset times identical to the Dual-DIST trials. Participants were instructed to focus on the tracking task and to inhibit saccades toward irrelevant visual stimuli (distractors), but to make saccades toward relevant stimuli (numbers). They were asked to mentally sum the successive numbers, and report the sum when given a cue. 


\section{FIG. 2}

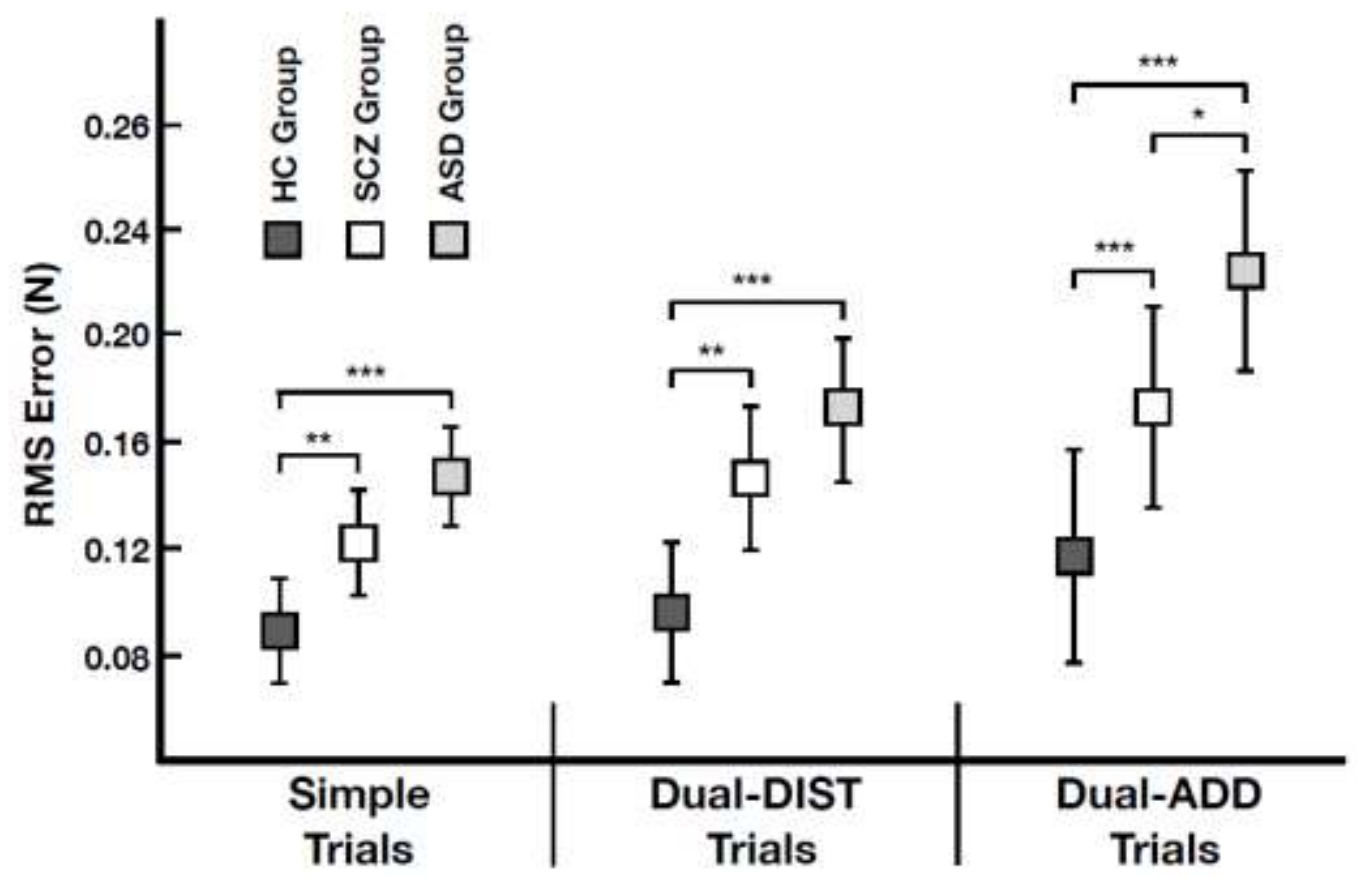

Fig 2. Force control precision.

Mean RMS force-tracking error (estimated marginal mean \pm vertical bars: 95\% confidence interval) during Single, Dual-DIST and Dual-ADD trials for the three groups: ASD (lighter grey), SCZ (white) and HC (darker grey). Significant differences (LSD fisher post-hoc tests for between group comparisons are shown as horizontal black brackets with: $*=p<0.05$; $* *=p<0.01, * * *=p<0.001)$. For sake of clarity, significant differences for within-group comparisons are not shown graphically, but detailed as follows: Dual-DIST led to increased error compared to Single-task only in patient groups (SCZ: $p=0.003$; ASD: $p=0.02$, HC: $\mathrm{p}=0.17$ ). Dual-ADD trials led to increased error compared to Single-task in all groups (SCZ: $\mathrm{p}<0.001 ;$ ASD: $\mathrm{p}<0.001 ; \mathrm{HC}: \mathrm{p}=0.002)$. 

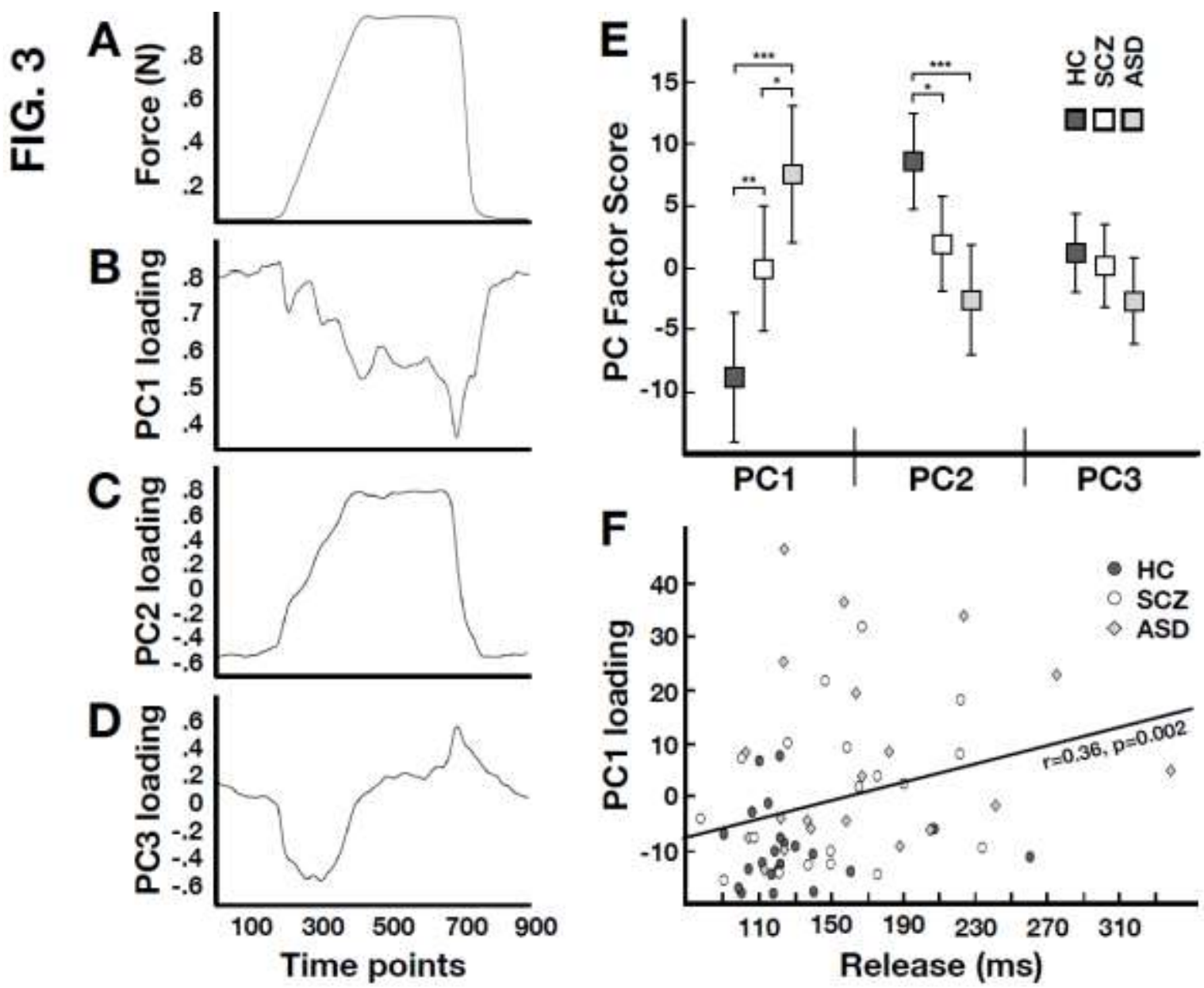

Fig 3. Principal component analysis of force-tracking.

A. Averaged force trajectory during the single-task condition across all participants. B-D. The first three principal component loading (PC1/PC2/PC3) as a function of time (900 sampled points). Note: PC1 loading decreases with increasing force, and is maximal at minimal force. E. Mean loading factor (estimated marginal mean \pm vertical bars: $95 \%$ confidence interval) for the first three PCs for the three groups: ASD (lighter grey), SCZ (white) and HC (darker grey). Significant differences (LSD fisher post-hoc tests for between group comparisons are shown as horizontal black brackets with: $*=\mathrm{p}<0.05 ; * *=\mathrm{p}<0.01$, $* * *=\mathrm{p}<0.001)$. F. Positive correlation between individual PC1 loading factor score and release duration across the three groups: ASD (light grey), SCZ (white) and HC (dark grey). 
FIG. 4

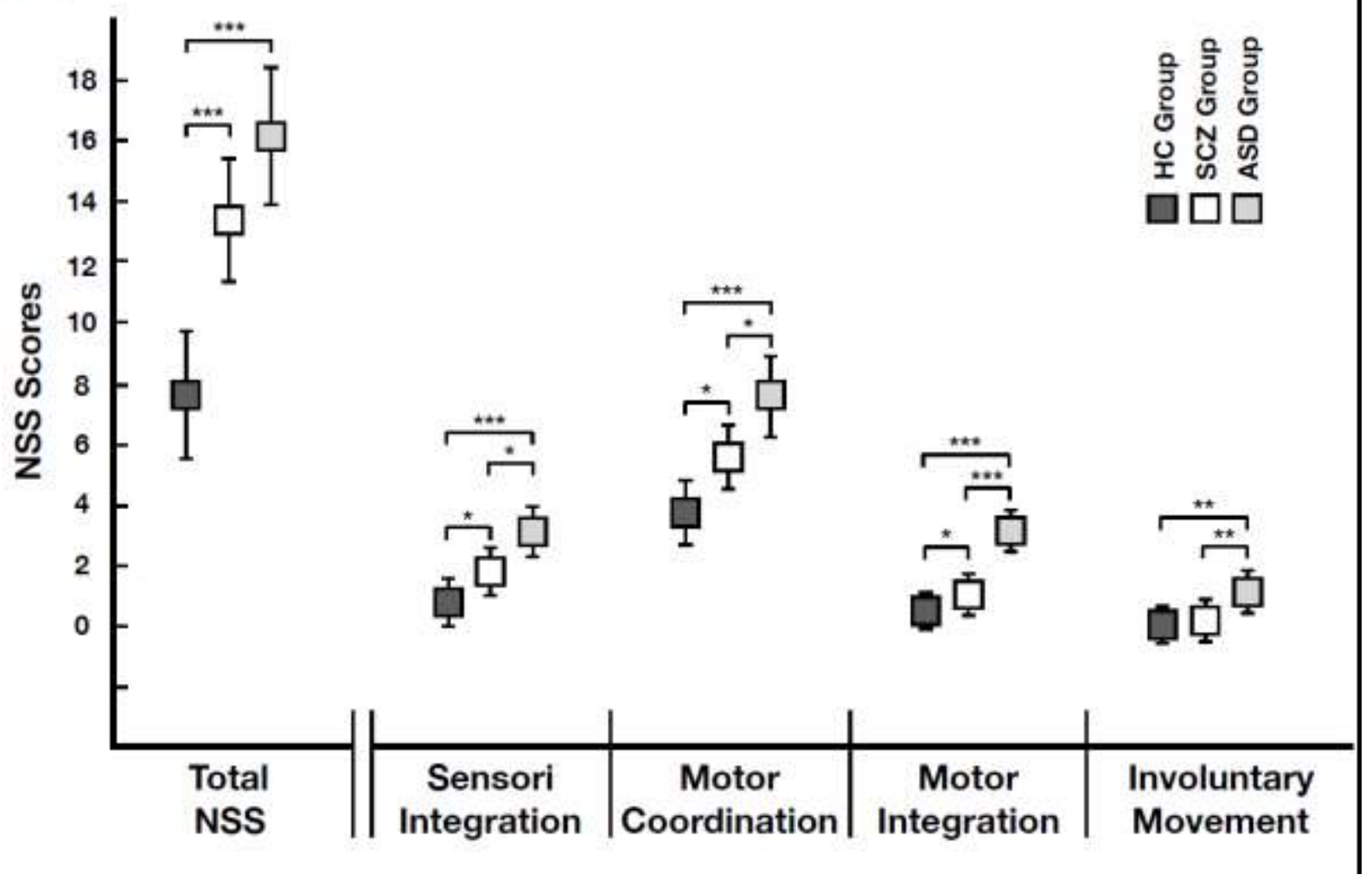

Fig 4. Neurological soft signs (NSS) scores.

NSS were clinically assessed. One total NSS score and four sub-scores were extracted for each group (mean \pm vertical bars: 95\% confidence interval): ASD (lighter grey), SCZ (white) and HC (darker grey). Significant differences (Mann-Whitney U tests for between group comparisons) are shown as horizontal black brackets with: $*=\mathrm{p}<0.05 ; * *=\mathrm{p}<0.01, * * *=\mathrm{p}<0.001$. 